\title{
IN VITRO ANTIOXIDANT ACTIVITY OF WHOLE PLANT OF LEPTADENIA PYROTECHNICA
}

\author{
Sangh Partap ${ }^{2},{ }^{*}$ Ujjwal Tewari $^{1}$, Kuldeep Sharma ${ }^{1}$ and Keshari Kishore Jha ${ }^{2}$ \\ ${ }^{1}$ Department of Pharmacology, College of Pharmacy, Teerthankar Mahaveer University, Moradabad \\ ${ }^{2}$ Department of Pharmaceutical Chemistry, College of Pharmacy, Teerthankar Mahaveer University, Moradabad, Uttar \\ Pradesh, India, 244001
}

*Corresponding Author's E- mail: uyjwal1985in@gmail.com

\begin{abstract}
The free radical scavenging potential of methanolic extract of Leptadenia pyrotechnica was studied on in vitro antioxidant models. The antioxidant potential was evaluated by determining the activity of hydrogen peroxide $(\mathrm{H} 2 \mathrm{O} 2)$ radicals scavenging and 1,1-diphenyl-2-picryl hydrazyl (DPPH) assay. In all these studies, a significant correlation existed between concentrations of the extract and percentage inhibition of free radicals. The extract was also shown to have high phenolic content i.e. $99.09 \pm 0.10 \mu \mathrm{g} / \mathrm{mg}$. These results clearly indicated that MELP could be a potential source of natural antioxidant and effective against free radical mediated diseases.
\end{abstract}

Keywords: Antioxidant, In vitro, Lagenaria siceraria, Reactive oxygen species

\section{INTRODUCTION}

Free radicals are natural by-products of our own metabolism. These are electrically charged molecules that attack cells, tearing through cellular membranes to react with the nucleic acids, proteins and enzymes present in the body ${ }^{1}$. Free radicals can cause lipid peroxidation in foods which leads to their deterioration ${ }^{2}$. Oxidation is well known to be major cause of foods and materials degradation ${ }^{3}$.Oxidation is a chemical reaction that transfers electron from a substance to an oxidizing agent. Oxidation reactions can produce free radicals which start chain reactions that damage cells ${ }^{1}$.The oxidants/free radicals are species with very short half life, high reactivity and damaging activity towards macromolecules like proteins, DNA and lipids 4 . Free radicals may be designated as molecular sharks that damage molecules in cell membranes, mitochondria (the cell's energy plants), DNA (the cell's intelligence) and are very unstable, tend to rob electrons from the molecules in the immediate surroundings in order to replace their own $\operatorname{losses}^{1}$. These species may be either oxygen derived (ROS) or Nitrogen derived (RNS). The most common reactive oxygen species include superoxide anion $\left(\mathrm{O}_{2}\right)$, hydrogen peroxide $(\mathrm{H} 2 \mathrm{O} 2)$, peroxyl radicals (ROO) and reactive hydroxyl radicals $(\mathrm{OH})$. The nitrogen derived free radicals are nitric oxide (NO), peroxy nitrite anion (ONOO), Nitrogen dioxide $\left(\mathrm{NO}_{2}\right)$ and Dinitrogen trioxide $\left(\mathrm{N}_{2} \mathrm{O}_{3}\right)^{4}$. Chemical compounds and reactions capable of generating potential toxic oxygen species/free radicals are referred to as 'prooxidants. In a normal cell there is an appropriate prooxidant: antioxidant balance. However, this balance can be shifted towards the pro-oxidant when production of oxygen species is increased or when levels of antioxidants are diminished. This state is called 'oxidative stress' and can result in serious cell damage if the stress is massive or prolonged ${ }^{4}$.In living organisms various ROSs can form in different ways including normal aerobic respiration, stimulated polymorph nuclear leukocytes \& macrophages and peroxisomes. These appear to be the main endogenous sources of most of the oxidants produced by cells. ${ }^{2}$ These attacks by free radicals, collectively known as oxidative stress, are capable of causing cells to lose their structure, function and can eventually destroy them. They are continuously produced by our body's use of oxygen such as in respiration and some cell-mediated immune functions. ${ }^{1}$ Free radicals attack the unsaturated fatty acid in the biomembranes resulting in membrane lipid peroxidation, a decrease in membrane fluidity, loss of enzyme, receptor activity and damage to membrane protein which lead to cell inactivation or death $^{5}$. In general, the reactive oxygen species circulating in the body tend to react with the electron of other molecules in the body and these also effect various enzyme systems and cause damage which may further contribute to conditions such as cancer, ischemia, aging, adult respiratory distress syndromes, rheumatoid arthritis, coronary heart disease, stroke, diabetes mellitus, rheumatic disease, liver disorders, multiple sclerosis, Parkinson's disease, autoimmune disease, Alzheimer's, AIDS and carcinogenesis ${ }^{3}$. Down's syndrome and ischemic reperfusion injury in different tissues including heart, liver, brain, kidney and gastro intestinal tract. The role played by ROS in stress induced gastric ulcer and inflammatory bowel diseases have been well established, as well as their involvement in the process of ageing ${ }^{1}$. The exogenous sources of ROS include electromagnetic radiation, cosmic radiation, UVlight, ozone, cigarette smoke and low wavelength electromagnetic radiations and endogenous sources are mitochondrial electron transport chain, oxidation of fat. ${ }^{2,4}$ Plants and animals maintain complex systems of multiple types of antioxidants, such as glutathione, vitamin $\mathrm{C}$ and vitamin $\mathrm{E}$ as well as enzymes such as catalase, 
superoxide dismutase and various peroxidases. Low levels of antioxidants or inhibition of the antioxidants enzymes, cause oxidative stress and may damage or kill cells ${ }^{1}$. The harmful and pathologic action of the free radicals can be reversed or blocked by antioxidant substances. Antioxidant substances scavenge the free radicals and detoxify the physiological system. Current research in the field of free radical biology has indicated a confirmation that foods and beverages mounted with antioxidants play an essential role in the prevention of cardiovascular and neurodegenerative diseases and cancer. ${ }^{5}$. As antioxidant is a molecule capable of slowing or preventing the oxidation of other molecules. Antioxidants terminate these chain reactions by removing free radical intermediates, and inhibit other oxidative agents i.e. thiols, ascorbic acid or polyphenols ${ }^{1}$.The antioxidants may be defined as "any substance, when present at low concentrations compared with that of an oxidizable substrate that significantly delays or prevents oxidations of that substrate". The term oxidizable substrate includes every type of molecule found in vivo. Antioxidant defense include the antioxidant enzymes like SOD, CAT, GSH-px, etc, low molecular agents and dietary antioxidants ${ }^{1}$.

\section{MATERIALS AND METHODS}

\section{Chemicals and Reagents}

All the drugs and chemicals used in the study were of analytical grade. 1,1-diphenyl-2-picryl hydrazyl (DPPH) reagent were obtained from Sigma Chemicals (St. Louis, MO, USA). Ascorbic acid and other chemicals used for evaluation of oxidative stress parameters were obtained from Sisco Research Laboratories (Mumbai).

\section{Plant material}

The plant of Leptadenia pyrotechnica was collected from "Kagore" village of Jaipur, Rajasthan, India in the month of January. It was authenticated by Dr. D. C. Saini, Sr. Scientist, Birbal Sahni Institute of Palaeobotany, Lucknow, Uttar Pradesh, India. [Voucher registration number 15531]

\section{Preparation of extract}

The successive extraction of powdered material was carried out in several batches using different solvents in increasing order of polarity in a soxhlet apparatus by hot percolation technique. The solvents used were petroleum ether, chloroform, acetone, methanol and distilled water. The powdered material of Leptadenia pyrotechnica was evenly packed in a soxhlet extractor for about 36 hours with different solvents. The temperature was maintained $\left(25^{\circ} \mathrm{C}-100^{\circ} \mathrm{C}\right)$ on an electric heating mantle with thermostat control. The extracts were then concentrated by evaporating the solvent under reduced pressure. Preliminary phytochemical studies were carried out on methanolic extract to assess the presence of various phytoconstituents ${ }^{6-7}$ and Antioxidant activity.

\section{IN-VITRO ANTIOXIDANT ACTIVITY}

The antioxidant properties of the $L$.pyrotechnica extract was determined with reference to hydrogen peroxide radical scavenging and DPPH assay method.
Hydrogen peroxide radical scavenging activity analysis

Hydrogen peroxide radical scavenging activity was determine by the method of Ruch et al. (1984). ${ }^{8}$ Hydrogen peroxide $\left(\mathrm{H}_{2} \mathrm{O}_{2}\right)$ is a biologically important oxidant because of its ability to generate the hydroxyl radical which is extremely potent. The ability of the hydroxyl radical to remove or add hydrogen molecules to unsaturated hydrogen bonds of organic lipids makes it potentially one of the most reactive oxidants in biological systems. It's very short half-life, however, restricts its diffusion capability and its potency. ${ }^{9,10}$

A solution of $\mathrm{H}_{2} \mathrm{O}_{2}(40 \mathrm{mM})$ was prepared in phosphate buffer ( $\mathrm{pH}$ 7.4). Different concentrations of $L$. pyrotechnica $(10-100 \mu \mathrm{g} / \mathrm{ml})$ in phosphate buffer were added to a $\mathrm{H}_{2} \mathrm{O}_{2}$ solution $(0.6 \mathrm{ml}, 40 \mathrm{mM})$. The absorbance value of the reaction mixture was recorded at $230 \mathrm{~nm}$. Blank solution was containing phosphate buffer without $\mathrm{H}_{2} \mathrm{O}_{2}$. The percentage of $\mathrm{H}_{2} \mathrm{O}_{2}$ scavenging of $L$. Pyrotechnica and Ascorbic acid as standard compound was calculated as

$\mathrm{H}_{2} \mathrm{O}_{2}$ radical scavenging activity $(\%)=\left[\left\{\mathrm{Ao}-\mathrm{A}_{1} / \mathrm{Aoo}\right\}\right]$ $\times 100$.

Where, Ao is the absorbance of the $\mathrm{H}_{2} \mathrm{O}_{2}, \mathrm{~A}_{1}$ is the absorbance of the presence of the extract in $\mathrm{H}_{2} \mathrm{O}_{2}$ solution. ${ }^{11,12}$

\section{1, 1-Diphenyl-2-picryl-hydrazyl (DPPH•) free radical scavenging activity}

The free radical scavenging activity of DPPH was determine by the method of Gadow et al. ${ }^{13}$ of Leptadenia pyrotechnica was estimated by this method, where in the bleaching rate of the stable free radical, $\mathrm{DPPH} \bullet$ is monitored at a characteristic wavelength in the presence of the sample. In its radical form, DPPH• absorbs at $517 \mathrm{~nm}$, but upon reduction by an antioxidant or a radical species its absorbance decreases. Briefly, 0.1 $\mathrm{mM}$ solution of DPPH (weigh $0.399 \mathrm{mg}$ of DPPH and dissolve in $50 \mathrm{ml}$ of methanol) in methanol was prepared and $1 \mathrm{ml}$ of this solution was added to $3 \mathrm{ml} \mathrm{L}$. pyrotechnica solution (stock solution of $L$.pyrotechnica was prepared by dissolving in methanol) in methanol at different concentration $(25-250 \mu \mathrm{g} / \mathrm{ml})$. Thirty minutes later, the absorbance was measured at $517 \mathrm{~nm}$. Lower absorbance of the reaction mixture indicates higher free radical scavenging activity.

The $1 \mathrm{ml}$ Dpph solution is mixed with $3 \mathrm{ml}$ of methanol and the absorbance is recorded as blank.

The DPPH • radical scavenging activity was calculated according to the following equation.

$$
\begin{gathered}
\text { DPPH radical scavenging activity }(\%)=\left[\left\{A o-A_{l} / A o\right\}\right] \\
\times 100 .
\end{gathered}
$$

Where, Ao is the absorbance of the DPPH $\bullet, A_{1}$ is the absorbance of the presence of the extract in DPPH• solution. ${ }^{11,14,15}$

\section{RESULTS}

Hydrogen peroxide radical scavenging activity analysis:- 
Hydrogen peroxide radical scavenging of $L$. pyrotechnica whole plant methanolic extract was estimated by using ascorbic acid solution as standard. The inhibition data (Table no. 1 and Table no. 2) were recorded against the selected concentrations $(10-100$ $\mu \mathrm{g} / \mathrm{ml})$.

Standard inhibition curve for Hydrogen peroxide radical scavenging of ascorbic acid (Fig no. 1) and for methanolic extract of whole plant of L. pyrotechnica (Fig no. 2) were plotted. From these $\mathrm{IC}_{50}$ values of percentage inhibition of hydrogen peroxide radical scavenging of the Ascorbic acid and methanolic extract were calculated using regression equation (Table no. 3 ).

Table 1: \% Inhibition data of hydrogen peroxide radical scavenging of ascorbic acid

\begin{tabular}{|c|c|}
\hline Conc. of Ascorbic acid $(\boldsymbol{\mu g} / \mathbf{m l})$ & $\%$ Inhibition \\
\hline 10 & 7.2 \\
\hline 20 & 15.2 \\
\hline 30 & 24.49 \\
\hline 40 & 32.3 \\
\hline 50 & 45.3 \\
\hline 60 & 53 \\
\hline 70 & 57.9 \\
\hline 80 & 64.8 \\
\hline 90 & 72.5 \\
\hline 100 & 82.7 \\
\hline
\end{tabular}

Table 2: \% Inhibition data of hydrogen peroxide radical scavenging by $L$. pyrotechnica methanolic extract of whole plant

\begin{tabular}{|c|c|}
\hline $\begin{array}{c}\text { Conc. of methanolic L. pyrotechnica } \\
\text { extract of whole plant }(\boldsymbol{\mu g} / \mathbf{m l})\end{array}$ & \% Inhibition \\
\hline 10 & 14.28 \\
\hline 20 & 21.42 \\
\hline 30 & 25 \\
\hline 40 & 25.42 \\
\hline 50 & 35.71 \\
\hline 60 & 39.28 \\
\hline 70 & 58.57 \\
\hline 80 & 59.14 \\
\hline 90 & 69.85 \\
\hline 100 & 78.57 \\
\hline
\end{tabular}

Table 3: Hydrogen peroxide radical scavenging $\mathrm{IC}_{50}$ of Ascorbic acid and methanolic whole plant extract of L. pyrotechnica.

\begin{tabular}{|c|c|}
\hline Sample & IC $_{\mathbf{5 0}}$ \\
\hline Ascorbic acid & $60.38 \mu \mathrm{g} / \mathrm{ml}$ \\
\hline $\begin{array}{c}\text { Methanolic whole plant } \\
\text { extract of } \\
\text { L. pyrotechnica }\end{array}$ & $65.48 \mu \mathrm{g} / \mathrm{ml}$ \\
\hline
\end{tabular}

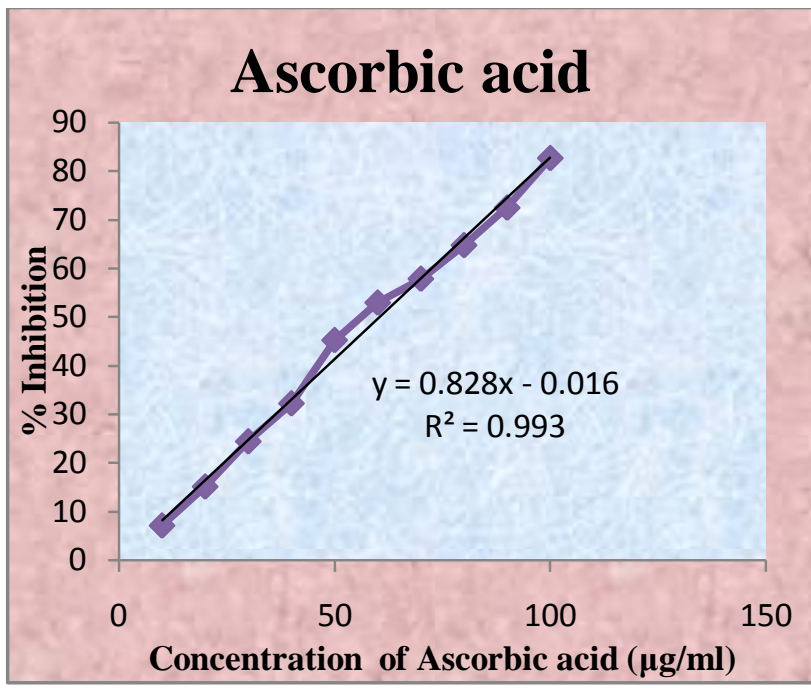

Figure 1: Standard inhibition curve of hydrogen peroxide radical scavenging of ascorbic acid

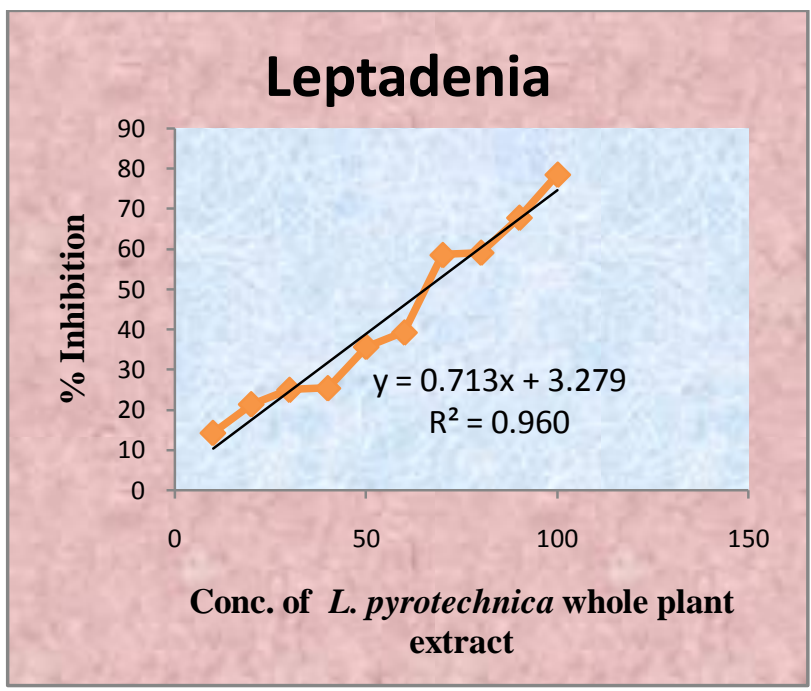

Figure 2: \% Inhibition curve of methanolic $L$. pyrotechnica whole plant extract.

$\mathrm{IC}_{50}$ value for standard (Ascorbic acid) and the methanolic plant extract of $L$. pyrotechnica extract were $60.98 \mu \mathrm{g} / \mathrm{ml}$ and $65.48 \mu \mathrm{g} / \mathrm{ml}$ respectively which represent the antioxidant potential of the standard and extract samples.

Hydrogen peroxide concentration decreased by scavenger compound by accelerating the conversion of $\mathrm{H}_{2} \mathrm{O}_{2}$ to $\mathrm{H}_{2} \mathrm{O}$ depending on the antioxidant potential of the component present in the extract and therefore absorption value also decreased. This was due to free radical scavenging activities of ascorbic acid and methanolic plant extract of L. pyrotechnica. ${ }^{8,11}$

\section{DPPH Assay:-}

DPPH (2,2-diphenyl-1-picrylhydrazyl) free radical scavenging activity of methanolic $L$. pyrotechnica whole plant extract was estimated by using ascorbic acid solution as standard. The absorbance data (Table 4 and Table 5) were recorded against the selected concentrations ( $25,50,100,150,200,250 \mu \mathrm{g} / \mathrm{ml})$. 
Table 4: \% Inhibition data for DPPH assay of ascorbic acid

\begin{tabular}{|c|c|}
\hline Conc. of Ascorbic acid $(\boldsymbol{\mu g} / \mathbf{m l})$ & \% Inhibition \\
\hline 25 & 42.15 \\
\hline 50 & 47.21 \\
\hline 100 & 47.72 \\
\hline 150 & 51.35 \\
\hline 200 & 55.21 \\
\hline 250 & 58.88 \\
\hline
\end{tabular}

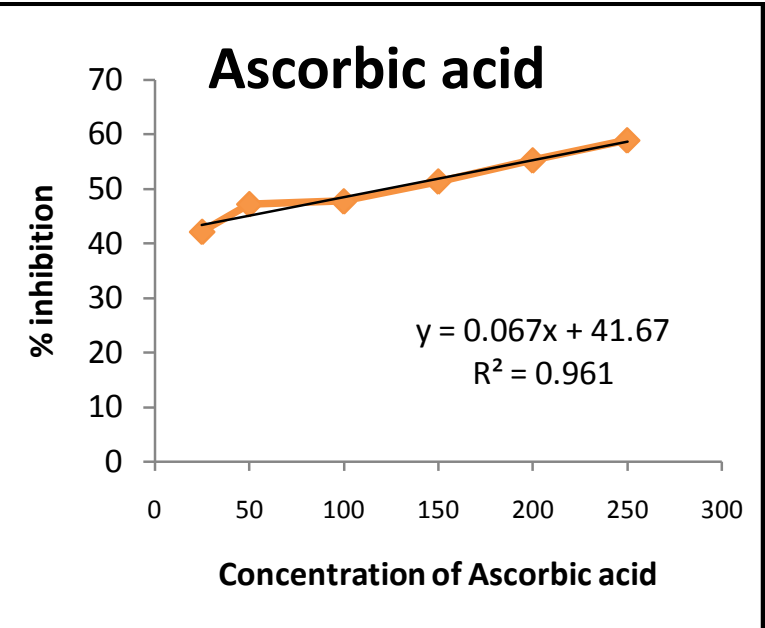

Figure 3: \% Inhibition DPPH assay curve of Ascorbic acid

Table 5: \% Inhibition data for DPPH assay of $L$. pyrotechnica extract

\begin{tabular}{|c|c|}
\hline $\begin{array}{c}\text { Conc. of } \boldsymbol{L} . \text { pyrotechnica extract } \\
(\boldsymbol{\mu g} / \mathbf{m l})\end{array}$ & \% Inhibition \\
\hline 25 & 38.59 \\
\hline 50 & 43.18 \\
\hline 100 & 46.36 \\
\hline 150 & 49.88 \\
\hline 200 & 53.04 \\
\hline 250 & 57.18 \\
\hline
\end{tabular}

Table 6: DPPH assay $\mathrm{IC}_{50}$ of ascorbic acid and $L$. pyrotechnica whole plant methanolic extract

\begin{tabular}{|c|c|}
\hline Sample & IC $_{\mathbf{5 0}}$ of DPPH assay \\
\hline Ascorbic acid & $121.69 \mu \mathrm{g} / \mathrm{ml}$ \\
\hline $\begin{array}{c}\text { Whole plant methanolic extract } \\
\text { of L. pyrotechnica }\end{array}$ & $152.46 \mu \mathrm{g} / \mathrm{ml}$ \\
\hline
\end{tabular}

$\mathrm{IC}_{50}$ values for standard (Ascorbic acid) and the methanolic whole plant extract of $L$. pyrotechnica were $121.69 \mu \mathrm{g} / \mathrm{ml}$ and $154.69 \mu \mathrm{g} / \mathrm{ml}$ respectively represents the antioxidant potential of the standard and extract.

The antioxidant potential of $L$. pyrotechnica was assessed by DPPH assay. The DPPH assay provided on the measurement of scavenging activity of antioxidant toward the stable radical DPPH: Antioxidant reduced the radical to the corresponding hydrazine. $\mathrm{DPPH}^{\cdot}$ Radical react with suitable reducing agent, the electrons became paired off and the solution lost colour stoichimetrically depending on the number of electron taken up. The plant extract show reduction in absorption value in DPPH assay is due to radical scavenging activity of ascorbic acid and methanolic whole plant extract of L.pyrotechnica.

\section{DISCUSSION}

Free radicals are chemical entities that can exist separately with one or more unpaired electrons. The propagation of free radical can brings about many adverse reactions leading to extensive tissue damage. Lipid proteins are all susceptible to attack by free radical. Many plant species with antioxidant activities act as protective agents against these radicals. In the present investigation potent antioxidant activity of methanolic whole plant extract of L.pyrotechnica was observed using different methods. However the efficacy of extract to scavenge the different radicals differed in each method depending upon the mechanism of free radical scavenging and assay methodology.

The result of DPPH scavenging activity assay in this study indicated that the plant was potently active. This suggested that the plant extract did contain compounds that could be capable of donating hydrogen to a free radical in order to remove the odd electron which is responsible for the radical's reactivity.

$\mathrm{H}_{2} \mathrm{O}_{2}$ is a weak oxidising agent and can inactivate a few enzymes directly, usually by oxidation of essential thiol (-SH) groups. It can cross cell membranes rapidly. Once inside the cell, $\mathrm{H}_{2} \mathrm{O}_{2}$ can probably react with $\mathrm{Fe} 2+$, and /or $\mathrm{Cu} 2+$ ions to form hydroxyl radical and this might be the origin of many of its toxic effects ${ }^{17}$. It is therefore biologically advantageous for cells to control the amount of $\mathrm{H}_{2} \mathrm{O}_{2}$ getting accumulated. Scavenging of $\mathrm{H}_{2} \mathrm{O}_{2}$ by the 
plant extract could be attributed to its phenolics which donate electron to $\mathrm{H}_{2} \mathrm{O}_{2}$, thus reducing it to water. The extract was capable of scavenging $\mathrm{H}_{2} \mathrm{O}_{2}$ in a concentration dependent manner.

\section{CONCLUSION}

The results obtained in the present study indicated that L.pyrotechnica extract exhibited free radical scavenging activity against hydrogen peroxide and DPPH•. The

\section{REFERENCE}

1. Vaibhav D Aher, Arunkumar wahi, Abhijit M. pawdey; "Antioxidants as Immunomodulator: an expanding research avenue" Review article; International journal of current pharmaceutical research; 2011, vol. 3 ; issue 1; pp no. 8-10.

2. S.S. Naphade et.al Antioxidant Activity of different extracts of plant Tricholepsi Glaberrima DC (Asteraceae); International Journal of Pharm Tech Research. vol,No. 5, pp 502-505.

3. 3Mohammad hassanzadeh-khayyat, Mehdi mojarab and Seyyed ahmad emami, "Antioxidant activity of methanolic extracts of different species of Artemisia from Irab",Pharmacology online, 2009, 2: 797807, page no.797.

4. Rathore K.S, Sisodia S.S. and panchawat S.,"A review on herbal antioxidant", International Journal Of Pharma Tech Research; jan-march2010, vol. 2 ; issue 1; pp no. 232-239.

5. Manjir Sarma kataki ; Anti bacterial activity, Invitro antioxidant activity and anthelmintic activity of Ethaolic extract of ANANAS Comosus L. Teder Leaves;

Pharmacologyonline, 2010, 2; pp no. 308-319.

6. Agarwal SS. Paridhavi M. Herbal Drug Technology. University Press, Pvt. Ltd. Hyderabad; 2007; p. 326

7. Khandelwal KR. Practical Pharmacognosy. $9^{\text {th }}$ ed. Nirali Prakashan Pune; 2008; p. 148-157.

8. Ranju Pal, Kundlik Girhepunje, Ashutosh Upadhayay And Thirumoorthy N., "Antioxidant and free radical scavenging activity of ethanolic extract of the root of Morinda citrifolia" African journal of pharmacy and pharmacology; 2012; vol. 6; issue 5; pp. 278-282.

9. Priscilla M Clarkson and heather S Thompson, "Antioxidant: what role do they play in physical activity and health?" The American journal of clinical nutrition; 2012; pp. 637S-646S.

10. P.K.J.P.D. Wanasundara and F. Shahidi' "Antioxidant: Science, technology, and Applications" Bailey's industrial oil and fat products, $6^{\text {th }}$ edition; vol.6; pp.431-489. overall antioxidant activity of L.pyrotechnica might be attributed to its polyphenolic content and other phytochemical constituents. The findings of the present study suggested that L.pyrotechnica could be a potential source of natural antioxidant that would have great importance as therapeutic agents in preventing or slowing the progress of reactive oxygen species and associated oxidative stress related degenerative diseases.

11. Nitai Chand Chaulya, Pallab Kanti Haldar, Arup Mukherjee "In Vitro Free Radical Scavenging Activity Of Methanolic Extract Of Rhizome Of Cyperus Tegetum Roxb.(CYPERACEAE)" International Journal of Current Pharmaceutical Research; 2010; vol.2; issue 3; pp. 39-43.

12. Buricova L., Andjelkovic M., cermakova A., Reblova Z., Jurcek O., Kolehmainen E., Verhe R., and Kvasnicka F. "Antioxidant capacity and antioxidants of strawberry, blackberry and raspberry leaves" Czech J. food sci., 2011, vol. 29; issue 2; pp. 181-189.

13. Lucie Buřičová , Mirjana Andjelkovic, Anna Čermáková,Zuzana Rébl ová, Ondřej Jurček, Erkki Kolehma inen, Roland Verhé and František Kvasn ička6," Antioxidant Capacity and 14Antioxidants of Strawberry Blackberry, and Raspberry Leaves" Czech J. Food Sci.; 2011 vol. 29; issue 2; pp. 181-189.

14. R.N. mishra, veena singh, "In-vitro antioxidant activity of megaext of triamrit" International Journal of research in pharmacy and chemistry; 2011; vol.1; issue 1; pp. 36-39.

15. Sonkar R. and Mishra R.N., "Antioxidant activity of triphala Megaext" International Journal of research in pharmaceutical and biomedical sciences;; 2011, Vol. 2; Issue 2; pp. 579-582.

16. Nitai Chand Chaulya, Pallab Kanti Haldar, Arup Mukherjee "In Vitro Free Radical Scavenging Activity Of Methanolic Extract Of Rhizome Of Cyperus Tegetum Roxb.(CYPERACEAE)" International Journal of Current Pharmaceutical Research; 2010; vol.2; issue 3; pp. 39-43.

17. Halliwell, B. \& gutteridge, J. M. C. Formation of a thiobarbituric-acid-reactive substance from deoxyribose in the presence of iron salts. The role of superoxide and hydroxyl radicals, Federation of European Biochemical Societies (FEBS) Letters, 1981, 128: 347-352. 